Please do not remove this page

RMIT

UNIVERSITY

\title{
Life satisfaction amongst police officers working in the area of child abuse investigation
}

Powell, Martine; Tomyn, Adrian

https://researchrepository.rmit.edu.au/esploro/outputs/9921858342801341/filesAndLinks?institution=61RMIT_INST\&index=null

Powell, M., \& Tomyn, A. (2011). Life satisfaction amongst police officers working in the area of child abuse investigation. International Journal of Police Science and Management, 13(2), 187-194.

https://doi.org/10.1350/ijps.2011.13.2.225

Document Version: Published Version

Published Version: https://doi.org/10.1350/ijps.2011.13.2.225

Repository homepage: https://researchrepository.rmit.edu.au

(C) Vathek Publishing Ltd

Downloaded On 2023/04/27 00:12:30 +1000

Please do not remove this page 
Citation:

Tomyn, A and Powell, M 2011, 'Life satisfaction amongst police officers working in the area of child abuse investigation', International Journal of Police Science and Management, vol. 13, no. 2, pp. 187-194.

\title{
Life satisfaction amongst police officers working in the area of child abuse investigation
}

\author{
Martine B. Powell ${ }^{\ddagger}$ and Adrian J. Tomyn ${ }^{\dagger}$ \\ $\ddagger$ (Corresponding author) School of Psychology, Deakin University, 221 Burwood Hwy, \\ Burwood, 3125, Australia. Tel: 6139244 6106; Fax: 6139244 6858; email: \\ martine.powell@deakin.edu.au. \\ †School of Health Sciences, Discipline of Psychology, RMIT University, Bundoora, \\ Australia.
}

Submitted 27 September 2010; revision submitted 13 February 2011; accepted 16 February 2011

Keywords: stress and policing, vicarious trauma, life satisfaction

\begin{abstract}
Martine Powell is Professor of Psychology and a widely recognised expert in the area of child abuse investigation. She has published over 130 papers on the topic; her focus has been investigative interview technique as well as the personal and organisational barriers that inhibit effective child abuse investigation and the identification of strategies for overcoming these.

Adrian Tomyn is an early career researcher who specialises in the area of mental wellbeing. He completed his PhD on the topic of life satisfaction, under the supervision of Professor Robert Cummins (a leading international expert on the topic).
\end{abstract}

\section{Abstract}

Child abuse investigation is an area of work reported to be associated with high levels of work stress. This potentially places professionals at risk of psychological harm and may lead to lower life satisfaction than in the general population. The current study examined this issue within a large sample of Australian police officers. Specifically, 214 officers working in the area of child abuse investigation responded to a single global measure of life satisfaction (LS) known to be highly related to other measures of subjective wellbeing
}

as well as clinical depression. The results revealed that, irrespective of the officers' gender or degree of exposure to child abuse cases, the mean score from LS score was within the expected adult normative range. Further, the overall incidence of low LS in this sample (1.9 per cent) was not significantly different from the general population (4.3 per cent). The implications of these findings for police organisations are discussed.

\section{INTRODUCTION}

Child abuse investigation is an area of work reported to be associated with high levels of work stress, placing professionals who work in the area at a higher risk of psychological harm than the general population (Chouliara, Hutchison, \& Karatzias, 2009; Stevens \& Higgins, 2002). In the clinical literature, the association between exposure to traumatic case material (eg, child sexual abuse) and trauma-related symptoms (eg, anxiety, depression) amongst professionals is well established. The risk of developing such symptoms seems to be heightened amongst females, those with a personal history of childhood maltreatment
International Journal of Police Science and Management, Vol. 13 No. 2, 2011, pp. 187-194 DOI: 10.1350/ijps.2011.13.2.225 
and those who carry relatively large caseloads (Brady, Guy, Poelstra, \& Brokaw, 1999; Schauben \& Frazier, 1995).

The risk of psychological injury from exposure to traumatic case material is relevant to all professionals in the field of child abuse investigation (eg, social workers, therapists) including police officers (Coman, Evans, Stanley, \& Burrows, 1991; Dantzer, 1987; Kroes, Hurrell, \& Margolis, 1974; Terry, 1981). Indeed, police officers are less likely than other professionals to seek therapeutic intervention to prevent or moderate their stress reactions (Follette et al., 1994). Further, police officers are less likely to receive adequate training to prepare them to handle child sexual abuse investigations (Daly, 2005) and are more likely to selfmedicate with the use of alcohol and other drugs, which compounds trauma symptoms in the long term (Cross \& Ashley, 2004). Poor conviction rates and exposure to offenders as well as victims may also heighten feelings of compassion fatigue amongst police (Violanti \& Gehrke, 2004; Wright, 2004; Wright, Powell, \& Ridge, 2006).

Given the potentially negative psychological impact of working in the area of child abuse investigation, law enforcement organisations need to ensure that they provide work contexts and procedures that maximise worker safety. One such procedure, adopted in some jurisdictions, is to limit the time that professionals can work in the area (ie, impose maximum tenure: Powell \& Wright, 2009). Other strategies include education programmes and mandatory routine psychological assessment and therapeutic consultation. However, little research has investigated the relative efficacy of various procedures in minimising psychological or other injuries. Indeed, almost no research has examined the psychological functioning of police who work in this area. The research has been limited to eliciting professionals' perceptions about the nature of the stressors they face (eg, Wright et al., 2006) as opposed to using normative measures of mental and/or physical wellbeing to examine the functioning of professionals relative to the general population. The current study makes one small, albeit important, contribution to this area by implementing a global normative measure of subjective wellbeing in a large sample of officers; a measure that is known to be highly correlated with mood dysfunction and is moderately to highly correlated with health satisfaction (International Wellbeing Group, 2006).

Specifically, we asked child abuse investigators to respond to a single question, 'How satisfied are you with your life as a whole?', using an 11-point end-defined Likert scale $(0=$ Completely Dissatisfied; $5=$ Neutral; $10=$ Completely Satisfied). This item was first developed by Campbell, Converse, and Rodgers (1976) and is one of the most widely adopted global assessments of subjective wellbeing. Despite being a single item, it is reported to have adequate psychometric properties (Cummins, Eckersley, Pallant, Van Vugt, \& Misajon, 2003; Diener, Suh, Lucas, \& Smith, 1999) and high convergent validity with other frequently used measures of subjective wellbeing (International Wellbeing Group, 2006; Tomyn \& Cummins, 2010). More importantly for this study, scores on the single-item measure of life satisfaction are known to be a good global indicator of general pathology, for example, depression in Australia (Cummins et al., 2010) and suicide ideation overseas (Heisel \& Flett, 2004).

A robust phenomenon in the literature is that life satisfaction is normally a positive state of mind, with most people scoring in the positive range for life satisfaction (Cummins, 1995; Cummins \& Nistico, 2002; Diener, 2000; Headey \& Wearing, 1989, 1992). According to Cummins et al. (2010), 74 per cent of Australian adults participating 
in the Australian Unity Wellbeing Index scored in the 6-9 range measured using the aforementioned 0-10 Likert scale, irrespective of contextual life circumstances. Further, Cummins et al. reported that only 9 per cent of Australian adults score between 0 and 4 . Thus, it is normal for most people to experience a level of life satisfaction in the positive range of values offered by this measurement instrument.

Using mean life satisfaction (LS) scores obtained from the 22 surveys comprising the Australian Unity Wellbeing Index over the years 2001-2010, a normative range for LS amongst the Australian adult population has been generated. This normative range is reported to be between 7.59 and 7.92 (Cummins et al., 2010). Thus, a lower mean LS rating amongst individuals tested compared with the general population and a significantly higher proportion of responses in the $0-4$ response range compared with the general Australian adult population (9 per cent) would indicate that experienced child abuse investigators (as a group) have relatively poor subjective wellbeing and higher risk of pathology in the form of depression or anxiety (Cummins et al., 2010).

\section{STUDY AIMS AND HYPOTHESES}

This study examined LS amongst experienced child abuse investigators at four state law enforcement agencies in Australia. Specifically, our aim was to determine whether this line of work (reported to be associated with high levels of work stress) is associated with lower levels of LS compared to the general adult population. Based on the evidence that females are more likely to suffer vicarious trauma than males, we also hypothesised that female officers would have a significantly lower mean LS score than males, and that the frequency of responses in the $0-4$ range would be significantly higher for the female officers compared with the males. Finally, we hypothesised that the greater the officers' exposure to case material, the lower their mean LS score and the higher the frequency of responses in the $0-4$ range.

\section{METHOD}

\section{Participants}

The police officers were recruited through senior members of child abuse units at four state law enforcement agencies in Australia, over the years 2003 to 2009 . Of the 236 officers invited to take part, $214 \quad(128$ female and 86 male) agreed to be involved, representing a response rate of 90.7 per cent. While the officers were of various ranks, the majority were of senior constable or sergeant level, ${ }^{1}$ had more than 10 years' experience in the police force, and had considerable experience investigating child abuse (exposure to more than 100 cases). Apart from voluntary access to a therapist, however, each of our participants had little exposure to formal preparation or intervention for dealing with work-related stressors.

\section{Procedure and measures}

Officers completed a written questionnaire while they attended professional development workshops (as a group). The officers read an explanatory statement describing the study and their involvement before providing the written informed consent that enabled their responses to be included. Officers were aware at the time of completing the questionnaire that the results were confidential (no names or other identifying features were displayed on the forms).

\section{Life satisfaction}

This was measured with the single question, 'How satisfied are you with your life as a whole?', using the 11-point end-defined Likert scale $(0=$ Completely Dissatisfied; 
$5=$ Neutral; $10=$ Completely Satisfied) described previously.

\section{Years of experience in the police force}

Participants were asked to report the month and year in which they joined the police force so that the time between initial recruitment and the completion of the questionnaire could be calculated. Participants were grouped into the following four categories representing years of service: $1-4$ years, 5-10 years, 11-15 years and 16+ years.

\section{Number of prior interviews with children}

Participants indicated experience in interviewing children by estimating the most appropriate number of prior interviews conducted (ie, 0, 1, 3, 5, 10, 20, 30, 40, 50, 75, 100, 150, 200, 300, >300). Participants were then grouped into the following six categories: no prior interviews, 1-10 interviews, 11-20 interviews, 21-50 interviews, 51-100 interviews and 101+ interviews.

Participants were then grouped into the following four categories: 1-10 interviews, 11-20 interviews, 21-50 interviews, 51-100 interviews and 101+ interviews

\section{Number of prior interviews with an alleged adult offender}

Participants indicated experience in interviewing offenders by estimating the most appropriate number of prior interviews (ie, $0,1,3,5,10,20,30,40,50,75,100,150$, 200, 300, >300). Participants were then grouped as no prior interviews, 1-20 interviews, $21-50$ interviews, $51-100$ interviews and $101+$ interviews.

Note that there was no theoretical basis for grouping participants according to years of experience and number of interviews in the manner described above. Rather, participants were grouped into categories to ensure that there were an adequate number of cases in each group to test the predictions and identify any significant group differences that might exist on these variables.

\section{Data management and analysis}

SPSS software (version 17.0) was used for data screening and analysis. Levene's test of the assumption of equality of error variances between groups was assumed $(p>$ 0.05 ) for all analyses involving Analysis of Variance (ANOVA), and all results were interpreted at the level of $p<0.05$.

\section{RESULTS}

\section{Comparing life satisfaction scores with the adult normative range}

The mean score for LS in the current sample was $7.70(S D=1.37)$. This mean score is within the expected normative range for Australian adults (7.59-7.92). The incidence of low life satisfaction (LS between 0 and 4) in our sample of child abuse investigators was calculated and found to be 1.90 per cent. A test for the significance of difference of proportions was conducted (Glantz, 2002) and revealed that this was not significantly different from the Australian adult incidence of 4.3 per cent.

\section{Examination of individual factors associated with life satisfaction}

Table 1 presents the mean LS scores and the incidence of low LS scores across each of the individual factors examined: gender, length of service in years, number of prior investigative interviews with children and number of prior investigative interviews with alleged child abuse offenders. Exploratory analyses were conducted to investigate whether there were any differences and trends in LS scores and incidences of low LS amongst various subgroups within this sample of police officers. 
Table 1: Means, standard deviations and incidence of low LS in each interview group

\begin{tabular}{|c|c|c|c|c|c|c|}
\hline & & $N$ & Mean LS & $S D$ & $\begin{array}{l}n \\
(L S<4)\end{array}$ & $\begin{array}{l}\% \\
(L S<4)\end{array}$ \\
\hline \multirow[t]{2}{*}{ Gender } & Female & 128 & 7.87 & 1.37 & 3 & 2.34 \\
\hline & Male & 86 & 7.63 & 1.37 & 1 & 1.16 \\
\hline Total & & 214 & 7.70 & 1.37 & 4 & 1.90 \\
\hline \multirow[t]{4}{*}{ Years in service } & $1-4$ & 44 & 7.84 & 1.21 & 0 & 2.30 \\
\hline & $5-10$ & 84 & 7.92 & 1.40 & 2 & 2.38 \\
\hline & $11-15$ & 45 & 7.69 & 1.26 & 1 & 2.22 \\
\hline & $16+$ & 41 & 7.49 & 1.57 & 1 & 2.44 \\
\hline Total & & 214 & 7.70 & 1.37 & 4 & 1.90 \\
\hline \multirow[t]{6}{*}{ No. of prior interviews with children } & 0 & 12 & 7.00 & 2.13 & 1 & 8.33 \\
\hline & $1-10$ & 50 & 7.80 & 1.53 & 1 & 2.00 \\
\hline & $11-20$ & 22 & 7.59 & 1.10 & 0 & 0.00 \\
\hline & $21-50$ & 39 & 7.85 & 1.29 & 1 & 2.04 \\
\hline & $51-100$ & 34 & 8.30 & 1.38 & 1 & 2.94 \\
\hline & $101+$ & 57 & 7.70 & 1.18 & 0 & 0.00 \\
\hline Total & & 214 & 7.70 & 1.37 & 4 & 1.90 \\
\hline \multirow[t]{5}{*}{ No. of prior interviews with adult offender } & 0 & 11 & 7.64 & 1.63 & 0 & 0.00 \\
\hline & $1-20$ & 25 & 7.32 & 1.84 & 2 & 8.00 \\
\hline & $30-50$ & 44 & 7.93 & 1.43 & 0 & 0.00 \\
\hline & $75-100$ & 40 & 7.88 & 1.24 & 1 & 2.50 \\
\hline & $150+$ & 93 & 7.79 & 1.39 & 1 & 1.07 \\
\hline Total & & 213 & 7.70 & 1.37 & 4 & 1.88 \\
\hline
\end{tabular}

\section{Gender}

An independent samples t-test was conducted to investigate the significance of difference between male and female mean LS scores. No significant effect for gender was observed $(p>0.05)$. Females reported a similar mean LS score $(M=7.87, S D=$ $1.37)$ to males $(M=7.63, S D=1.37)$ and likewise the incidence of low LS was similar for females (2.34 per cent) and males (1.16 per cent).

\section{Years in service}

A one-way ANOVA was conducted to investigate any group differences in mean LS scores amongst police officers according to years in service as a police officer. No significant effect of years in service on LS was found $(p>0.05)$. Likewise, the incidence of low LS was not significantly different between each of the four groups.

\section{Total interviews conducted with alleged child victims}

A one-way ANOVA was conducted to investigate group differences in mean LS scores amongst police officers according to number of interviews conducted with alleged child victims. No significant main effect was found. However, although not significant, it is noteworthy that the mean LS score amongst the 12 individuals with no prior interviews with an alleged victim was $7.0(S D=2.13)$, with one of these individuals scoring in the low LS range. Other than this observation, the incidences 
of low LS were not significantly different between each of the different groups.

\section{Total interviews conducted with alleged child sexual offenders}

A one-way ANOVA was conducted to investigate group differences in mean LS scores amongst police officers according to number of interviews conducted with an alleged adult offender. No significant main effect was found. Interestingly, the incidence of low LS was greatest amongst the 1-20 interview group (8 per cent); however, this incidence was not significantly different from any of the other groups.

\section{DISCUSSION}

Our study revealed that the overall mean LS for child abuse investigators was similar to that of the general population. Further, the overall incidence of low LS (ratings 0-4, which are indicative of depression) was not significantly different (1.9 per cent) compared with that of the general population (4.3 per cent). While the results of any one study and single item measure need to be interpreted with caution, we suspect that the results would generalise to other jurisdictions. The LS score was well within the expected range and, as with most prior studies using this global item (eg, Cummins et al., 2010), individuals' responses were treated as confidential. Further, the challenges that child abuse investigators report in our jurisdictions (eg, high workloads, limited professional development opportunities, inter-agency tensions, poor conviction rates) are widespread in other English-speaking jurisdictions (Wright et al., 2006).

In addition to finding null differences between LS ratings of child abuse investigators and of the general population, no significant differences were found among the subgroups of child abuse investigators. We hypothesised that female officers would have a lower mean LS score than males and that the frequency of responses in the $0-4$ range would be significantly higher for the female officers compared with the males; however there was no observed difference between the two genders. Further, degree of exposure to trauma material and associated workplace stressors (measured via length of service in years, number of prior investigative interviews with children and number of prior investigative interviews with alleged child abuse offenders) was not associated with subjective wellbeing. In contrast to the hypothesis that the greater the officers' exposure to case material, the lower the mean LS score would be and the higher the frequency of responses in the 0-4 range, LS scores did not significantly differ as a function of exposure to case material.

Given the strong link between LS and depressive symptomatology (for example, anxiety (Headey, Kelley, \& Wearing, 1993) and suicidal ideation (Heisel \& Flett, 2004), the current findings suggest that police officers working in the area of child abuse investigation have, as a group, no higher risk of depression than the general population. This should not be taken to mean that the stressors faced by child abuse investigators do not exceed individuals' coping strategies; case law (eg, New South Wales v. Seedsman, 2000) clearly shows that to be untrue. Rather, the current findings suggest that there would be little basis for imposing maximum tenure for all investigators as an appropriate course of action purely on psychological grounds. Indeed, considering the immense passion that some longstanding sexual assault investigators feel about their work, forcing maximum tenure on employees could feasibly compound psychological distress (Powell \& Wright, 2009).

Rather than supporting the need for global 'one-size-fits-all' tenure policies, our findings highlight the need for investment 
in research to identify systematically those few individual officers who are experiencing (or who may be at risk of developing) psychological problems and to examine the effectiveness of individually tailored support services to ensure appropriate assistance is provided in a timely manner. Such research is likely to require regular assessment and monitoring of all officers' psychological wellbeing. While many jurisdictions adopt longitudinal psychological assessment practices, it is rarely accompanied by good quality control assessment to establish the relation between psychometric data and various work environments, officer background characteristics and intervention procedures.

\section{Note}

1. Australian officers' ranks, from lowest to highest, are; Reservist, Constable, Senior Constable, Detective Senior Constable, Sergeant, Detective Sergeant, Senior Sergeant, Detective Senior Sergeant, Inspector, Detective Inspector, Chief Inspector, Detective Chief Inspector, Superintendent, Detective Superintendent, Chief Superintendent, Detective Chief Superintendent, Commander, Assistant Commissioner, Deputy Commissioner, Chief Commissioner.

\section{References}

Brady, J. L., Guy, J. D., Poelstra, P. L., \& Brokaw, B. F. (1999). Vicarious traumatization, spirituality, and the treatment of sexual abuse survivors: a national survey of women psychotherapists. Professional Psychology: Research and Practice, 30, 386-393.

Campbell, A., Converse, P. E., \& Rodgers, W. L. (1976). The quality of American life: perceptions, evaluations and satisfactions. New York: Russell Sage Foundation.
Chouliara, Z., Hutchison, C., \& Karatzias, T. (2009). Vicarious traumatisation in practitioners who work with adult survivors of sexual violence and child sexual abuse: literature review and directions for future research. Counselling \& Psychotherapy Research, 9, 47-56.

Coman, G. J., Evans, B. J., Stanley, R. O., \& Burrrows, G. D. (1991). Police officers' work environment and perceptions of stress: an Australian police sample. Journal of Police and Criminal Psychology, 7, 18-23.

Cornille, T. A., \& Woodard Meyers, T. (1999). Secondary traumatic stress among child protective service workers: prevalence, severity and predictive factors. Traumatology, $5,15-31$.

Cross, C. L., \& Ashley, L. (2004, October). Police trauma and addiction: coping with the dangers of the job. FBI Law Enforcement Bulletin, 24-32.

Cummins, R. A. (1995). On the trail of the gold standard for subjective wellbeing. Social Indicators Research, 35, 179-200.

Cummins, R. A., \& Nistico, H. (2002). Maintaining life satisfaction: the role of positive bias. Journal of Happiness Studies, 3, 37-69.

Cummins, R. A., Eckersley, R., Pallant, J., Van Vugt, J., \& Misajon, R. (2003). Developing a national index of subjective wellbeing: the Australian Unity Wellbeing Index. Social Indicators Research, 64, 159-190.

Cummins, R. A., Woerner, J., Weinberg, M., Perera, C., Gibson, A., Collard, J., \& Horfiniak, K. (2010). Australian Unity Wellbeing Index, Survey 23: the wellbeing of Australians - life better/worse, children and neighbourhood. Melbourne, VIC: Australian Centre on Quality of Life, Deakin University. Retrieved March 12, 2010, from http://www.deakin.edu.au/research/acqol/ auwbi/survey-reports/survey-023-reportpart-a.pdf

Daly, I. W. (2005). Police officers do not receive adequate training to prepare them to handle child sexual abuse investigations. Issues in Child Abuse Accusations, 15, 1-13.

Dantzer, M. L. (1987). Police-related stress: a critique for future research. Journal of Police and Criminological Psychology, 3, 43-52.

Diener, E. (2000). Subjective wellbeing: the science of happiness and a proposal for a 
national index. American Psychologist, 55, 34-43.

Diener, E., Suh, E. M., Lucas, R. E., \& Smith, H. L. (1999). Subjective well-being: three decades of progress. Psychological Bulletin, 25, 276-302.

Figley, C. R. (2002). Treating compassion fatigue. New York: Brunner-Routledge.

Follette, V. M., Polusny, M. M., \& Milbeck, K. (1994). Mental health and law enforcement professionals: trauma history, psychological symptoms, and impact of providing services to child sexual abuse survivors. Professional Psychology: Research E Practice, 25, 275-282.

Glantz, S. A. (2002). Primer of biostatistics (5th ed.). New York: McGraw-Hill.

Headey, B., Kelley, J., \& Wearing, A. (1993). Dimensions of mental health: life satisfaction, positive affect, anxiety and depression. Social Indicators Research, 29, 63-82.

Headey, B., \& Wearing, A. (1989). Personality, life events, and subjective wellbeing: toward a dynamic equilibrium model. Journal of Personality and Social Psychology, 57, 731-739.

Headey, B., \& Wearing, A. (1992). Understanding happiness: a theory of subjective wellbeing. Melbourne, VIC: Longman Cheshire.

Heisel, M. J., \& Flett, G. L. (2004). Purpose in life, satisfaction with life, and suicide ideation in a clinical sample. Journal of Psychopathology and Behavioral Assessment, 26, 127-135.

International Wellbeing Group. (2006). Personal Wellbeing Index - Adult (PWI-A).

Retrieved March 15, 2010 from Australian Centre on Quality of Life website: http:// www.deakin.edu.au/research/acqol/ instruments/wellbeing-index.htm

Kassam-Adams, N. (1995). The risks of treating sexual trauma: stress and secondary trauma in psychotherapists. Unpublished doctoral dissertation, University of Virginia, Charlottesville.

Kroes, W. M., Hurrell, J. J., Margolis, B. (1974). Job stress in police administrators.
Journal of Police Science and Administration, 3, 381-387.

Martin, C. A., McKean, H. E., \&

Veltkamp, L. J. (1986). Post traumatic stress disorder in police working with victims: a pilot study, Journal of Police Science and Administration, 14, 98-101.

New South Wales v Seedsman (2000) 217 ALR 583.

Powell, M. B., \& Wright, R. (2009, June). Stakeholders' perceptions of the new SOCIT and MDC model adopted by Victoria Police. Report submitted to Victoria Police. Not Published.

Schauben, L. J., \& Frazier, P. A. (1995). Vicarious trauma: the effects on female counselors of working with sexual violence survivors. Psychology of Women Quarterly, 19, 49-64.

SPSS for Windows: Release 17.0. (2008). Chicago, IL: SPSS Inc.

Stevens, M., \& Higgins, D. J. (2002). The influence of risk and protective factors on burnout experienced by those who work with maltreated children. Child Abuse Review, 11, 313-331.

Terry, W. C. (1981). Police stress: the empirical evidence. Journal of Police Science and Administration, 9, 61-75.

Tomyn, A. J., \& Cummins, R. A. (2010). The subjective wellbeing of high-school students: validating the Personal Wellbeing Index - school children. Social Indicators Research. doi: 10.1007/S11205-010-9668-6.

Violanti, J. M., \& Gehrke, A. (2004). Police trauma encounters: precursors of compassion fatigue. International Journal of Emergency Mental Health, 6, 75-80.

Wright, B. (2004). Compassion fatigue: how to avoid it? Palliative Medicine, 18, 3-4.

Wright, R., Powell, M. B., \& Ridge, D. (2006). Child abuse investigation: an indepth analysis of how police officers perceive and cope with daily work challenges. Policing: An International Journal of Police Strategies and Management, 29, 498-512. 